\title{
OPEN SURGERY FOR LIVER HYDATID DISEASE
}

\author{
Nikola Kolev ${ }^{1}$, Valentin Ignatov ${ }^{1}$, Georgi Ivanov ${ }^{1}$, Anton Tonev ${ }^{1}$, Vilian Platikanov², \\ Aleksandar Zlatarov ${ }^{1}$, Krasimir Ivanov ${ }^{1}$ \\ ${ }^{1}$ First Clinic of Surgery and ${ }^{2}$ Department of Anesthesiology and Intensive Care, \\ St. Marina University Hospital of Varna
}

\begin{abstract}
Hydatid cyst disease is a cosmopolitan parasitosis. E. granulosis species prevails in most countries around the world and especially in the Mediterranean region. We performed A retrospective literature search on liver hydatid cysts was carried out in ScienceDirect, Scopus, Web of Knowledge, InCites, and MEDLINE data-bases for the period 2000-2012. According to recent literature data, liver is the most commonly affected organ. The principles of surgical approach to the liver hydatid disease include the following: i) neutralization of the parasite; ii) evacuation of the cyst and removal of the germinative layer, and iii) treatment of the remaining cavity. The marsupialization of the remaining cyst is not accepted in case of suppurated hydatid cyst. There are numerous opinions about the most efficient scolicidal solution. The most intractable problem is the approach to the residual cavity of hydatid cyst. Major postoperative complications reported by different authors are mainly inflammatory processes. The radical surgical method is indicated in case of peripherally located hydatid cysts, several cysts grouped in a liver segment or lobe, and cysts located in the left lateral hepatic lobe. The surgical method still remains the golden standard for treatment of liver hydatid cysts.
\end{abstract}

Key words: hydatid cyst, open surgery, endocyst removal, liver resection, data-bases

\section{INTRODUCTION}

Echinococcosis is widely spread parasitosis (20). E. granulosus species prevails in most countries around the world and especially in those in the Mediterranean region (11). It is one of the most debilitating parasitic diseases in humans. Compared with others, this zoonosis most often leads to prolonged disability, frequent recurrences, not uncommon to permanent disability and high mortality, making it a severe medico-social and

\footnotetext{
Address for correspondence:

Georgi Ivanov, $M D, P h D$

First Clinic of Surgery,

St. Marina University Hospital of Varna

1 Hristo Smirnenski Str., 9010 Varna, Bulgaria

e-mail:ghivanov@abv.bg
}

Received: October 2, 2012

Accepted: July 30, 2013 economic problem for our country. Literature data suggest that liver is the most commonly affected organ (19). The surgical approach is adopted as the primary treatment option for liver hydatid disease for many years.

\section{MATERIAL AND METHODS}

We performed retrospective literature retrieval in the following data-bases: ScienceDirect, Scopus, Web of Knowledge, InCites, and PubMed version of MEDLINE for the period 2000-2012. The following indexing terms were used: 'echinococcosis', 'hydatid disease', 'liver', 'echinococcal cyst' and 'surgical treatment'. In this survey, we present the current conventional surgical techniques, the advantages and disadvantages of the methods as well as their indications and contraindications.

\section{RESULTS}

The main purpose of the surgical method is to inactivate the scolices, to prevent dissemination in 
the abdomen, and to obliterate the remaining cavity. Several surgical approaches have been introduced to eliminate residual cavity predisposed to complications. That is why some surgical methods such as marsupialization have been already dismissed from practice (14).

Conventional surgery is the primary treatment option indicated in any cases of hydatid cysts registered - liver cysts or cysts combined with other organ sites, uncomplicated or complicated cysts. The other methods of treatment are alternative or complementary. However, the combination of all the methods of treatment is acceptable and recommended in multiple echinococcosis (1).

Intervention techniques are conservative (processing and closing of the cavity with or without resection of portions of the capsule) and radical (surgery of liver tissue).

There are reasons why the closed methods are the most widely recommended and implemented in case of open bile ducts. Postoperative period is the shortest and without complications. Antibiotic prophylaxis is indicated and useful.

Placement of a tube drain or drainages leads to contamination of the remaining cavity after 4872 hours. There is a higher risk for subphrenic collection of fluids or external biliary fistula. Antibiotic treatment is required.

It is possible to leave an opening of the cyst in the abdominal cavity only on strict indications such as superficially localized hydatid cyst, resection of the greatest part of the capsule, absence of infection and open biliary ducts. The marsupialization of the remaining cyst is not accepted in case of suppurated hydatid cyst.

Radical resection methods consist of removal of endo- and pericyst. They include cystpericystectomy, atypical and typical liver resections. The radical method is indicated in case of peripherally located hydatid cysts, several cysts grouped in a liver segment or lobe, and cysts located in the left lateral hepatic lobe. In order to perform radical surgical methods a highly experienced surgical team as well as well-developed intensive care unit is required.

The principles of surgical approach to the liver hydatid disease include the following: i) neutralization of the parasite; ii) evacuation of the cyst and removal of the germinative layer, and iii) treatment of the remaining cavity. The total surgical removal is the ideal treatment of the disease. This could be achieved by elimination of the germinative layer, the daughter cysts, the liquid and scolices, or by resection of the intact cyst including the pericystic tissues. Initially, regardless of the method, the cystic fluid must be neutralized (8). The peritoneal cavity must be protected in the process of cyst evacuation in order to prevent dissemination of the cyst. After the evacuation, the remaining cyst must be processed with a scolicidal agent. The use of formalin is prohibited because of the systematic effects (4) and possible sclerosing cholangitis $(3,9)$.

There are numerous opinions about the most efficient scolicidal solution $(3,9)$. There exist many reagents such as chlorhexidine gluconate, $80 \%$ ethanol, hypertonic $\mathrm{NaCl}$ solution, and $0,5 \%$ silver nitrate. Usage of $20 \% \mathrm{NaCl}, 95 \%$ ethanol and povidoneiodine as scolicidal agents as an established method was reported (7); however, some authors challenged their use in multichamber cysts (7).

The second step is approaching the cyst cavity. The most intractable problem is the approach to the residual cavity of hydatid cyst. If there is a cystobiliaric communication, several modalities depending on the amount of this communication are offered (16). If there is involvement of the bile vessel sized up to $5 \mathrm{~mm}$ in diameter, a suture is applied. When communicating with a larger vessel, exploration of the ductus choledochus is offered. Kehr-drainage or internal drainage can be applied in cases with conservative surgical methods (5). On the other hand, cysts located peripherally or in the left lateral hepatic lobe should be treated with radical surgical techniques, thus eliminating the need for bile duct exploration or drainage (10). Some authors reported the usefulness of preoperative endoscopic retrograde cholangiopancreatography as a therapeutic and diagnostic method (15). Numerous techniques were proposed to deal with the residual cavity in order to prevent bile leakage and formation of biliary fistula or abscess. If possible, the cavity should be obliterated with capitonage or omentoplastics. Hepatic resection, pericystectomy, omentoplastics, capitonage, cystojejunal anastomosis, introflexy and, finally, primary closure of the cavity were suggested (18). Depending on 
Nikola Kolev, Valentin Ignatov, Georgi Ivanov et al.

cyst size and location and existing complications, the operator makes the choice for a particular surgical technique. The advantages of omentoplastics consist in a significant reduction of the hospital stay and the risk of biliary fistula. Introflexy is an alternative method for treatment of residual cavity. It can easily be performed in patients with peripheral cysts. Because of the risk of peritoneal dissemination and relapse, some authors prefer to use resection, however, this approach relates to a significant operational risk and is not applicable in certain cases (17).

Cystectomy or lobectomy can be done for a peripheral cyst (6). In central cyst localization, liver resection is not recommended while in peripheral cysts, segmentectomy could be performed.

Patients with comorbidities are treated by drainage of the cyst cavity. Drainage of the cavity significantly reduces complications such as infection of the residual cavity or biliary fistula. Some authors recommend cystectomy with omentoplastic or capitonage, cyst enteral anastomosis, superior lobectomy and external drainage. In uncomplicated cysts, these procedures provide a shorter hospitalization period compared to drainage. In the presence of daughter cysts in ductus choledochus, a choledochotomy and Kehr-drainage are recommended (12).

\section{Complications after open surgery}

Inflammatory processes represent major postoperative complications most commonly reported (12). According to the publications in the recent literature available, these complications include liver abscesses (in 2\%-5\%), wound infection (in 5\%) and pneumonia (in 2\%-4\% of patients undergoing open surgery). Liver abscess occurs in $1,5 \%$ of the patients operated on by conventional methods and wound infection in $2 \%$; the most severe complication is severe sepsis, shock, and death - in $1,5 \%$ of the patients (15). Postoperative bleeding after radical surgical methods such as pericystectomy occurs in $4-5 \%$ of the operated patients. Between one and two per cent of the patients develop biliary fistula, where the period of drainage is significantly prolonged (17). To the other complications belong early postoperative ileus and deep vein thrombosis. Between 20 and $30 \%$ of patients with deep vein thrombosis develop pulmonary thromboembolism (5).

\section{Indications for open surgery}

Surgery is indicated for the removal of large cysts with multiple daughter cysts, superficial liver cysts that can rupture spontaneously or as a result of trauma, suppurated cysts, cysts in communication with the biliary tract and/or compressing the adjacent organs (1).

\section{Contraindications for open surgery}

Surgery is contraindicated in the absence of informed consent by the patient, in elderly patients, pregnancy, comorbidity such as liver disease and diabetes mellitus, multiple echinococcosis, difficultly accessible cysts as well as non-viable cysts in patients with very small cysts (4).

\section{CONCLUSION}

The surgical method still remains the golden standard for treatment of liver hydatid cysts. Depending on the type of cyst and possible complications, the surgeon may choose between a conservative and radical technique. Postoperative complications are more common after radical surgery, although it is effective and safe procedure with lower rate of recurrence.

\section{REFERENCES}

1. Alfieri, S., G. B. Doglietto, F. Pacelli, G.

Costamagna, C. Carriero, M. Mutignani, et al.

Radical surgery for liver hydatid disease: a study of 89 consecutive patients.- Hepatogastroenterology, 44, 1997, No 14, 496-500.

2. Bülbüller, N., Y. S. Ilhan, C. Kirkil, A. Yeniçerioğlu, R. Ayten, Z. Cetinkaya. The results of surgical treatment for hepatic hydatid cysts in an endemic area.- Turk. J. Gastroenterol., 17, 2006, No 4, 273-278.

3. Cirenei, A., I. Bertoldi. Evolutions of surgery for liver hydatidosis from 1950 to today: analysis of a personal experience.- World. J. Surg., 25, 2001, No $1,87-92$.

4. Gollackner, B., F. Längle, H. Auer, A. Maier, M. Mittlböck, I. Agstner, et al. Radical surgical therapy of abdominal cystic hydatid disease: factors of recurrence.- World J. Surg., 24, 2000, No 6, 717-721.

5. Heirwegh, G., B. Claikens. Type I_hydatid_cyst of the liver: typical MRI features.- JBR-BTR, 88, 2005, No 3, 136-137. 
6. Khuroo, M. S., N. A. Wani, G. Javid, B. A. Khan, G. N. Yattoo, A.H. Shah, et al. Percutaneous drainage compared with surgery for hepatic hydatid cysts.New Engl. J. Med., 337, 1997, No 7, 881-887.

7. Kismet, K., B. Kilicoglu, O. Koru, M. Tanyuksel, M. T. Oruc, K. Sorkun, et al. Evaluation on scolicidal efficacy of propolis.- Eur. Surg. Res., 38, 2006, No 5, 476-481.

8. Kumar, R., S. N. Reddy, S. Thulkar. Intrabiliary rupture of hydatid_cyst: diagnosis with MRI and hepatobiliary isotope study.- Br. J. Radiol., 75, 2002, No 891, 271-274.

9. Langer, J. C., D. B. Rose, J. S. Keystone, B. R. Taylor, B. Langer. Diagnosis and management of hydatid disease of the liver. A 15-year North American experience.- Ann. Surg., 199, 1984, No 4, 412-417.

10. Mentes, A., Y. Yüzer, O. Ozbal, A. Coker, T. Ilter, A. Musoğlu. Omentoplasty versus introflexion for hydatid liver cysts.- J. R. Coll. Surg. Edinb., 38, 1993, No 2, 82-85.

11. Moore, J., V. Gupta, M. Y. Ahmed, B. Gociman. Hydatid_cyst disease: optimal management of complex_liver_involvement.-South. Med. J., 104, 2011, No 3, 222-224.

12. Moumen, M., M. E. El Alaoui, M. Mehhane, D. Jami, M. Mokhtari, F. el Fares. Resection of the prominent dome of a hydatid cyst of the liver: about 360 cases.- J. Chir. (Paris), 127, 1990, No 2, 83-86 (in French).

13. Ormeci, N., I. Soykan, A. Bektas, M. Sanoğlu, M. Palabiyikoğlu, M. Hadi Yasa, et al. A new percutaneous approach for the treatment of hydatid cysts of the liver.- Am. J. Gastroenterol., 96, 2001, No 7, 2225-2230.
14. Oruç, E., N. Yildirim, N. B. Topal, S. Kiliçturgay, S. Akgöz, G. Savci. The role of diffusion-weighted MRI in the classification of liver_hydatid_cysts and differentiation of simple cysts and abscesses from_hydatid_cysts.- Diagn. Interv. Radiol., 16, 2010, No 4, 279-287.

15. Safioleas, M., E. Misiakos, C. Manti, D. Katsikas, G. Skalkeas. Diagnostic evaluation and surgical management of hydatid disease of the liver.- World J. Surg., 18, 1994, No 6, 859-865.

16. Silva, M. A., D. F. Mirza, S. R. Bramhall, A. D. Mayer, P. McMaster, J. A. Buckels. Treatment of hydatid disease of the liver. Evaluation of a UK experience.- Dig. Surg., 21, 2004, No 3, 227-233.

17. Tasev, V., V. Dimitrova, K. Draganov, D. Bulanov, N. Popadiian, R. Gaidarski. Hepatic echinococcosis: radical or conservative surgical treatment.- Khirurgiya (Sofia), 58, 2002, No 2, 1013 (in Bulgarian).

18. Uravic, M., D. Stimac, T. Lenac, N. Ivanis, N. Petrosic, M. Rubinic, et al. Diagnosis and treatment of liver hydatid disease.- Hepatogastroenterology, 45, 1998, No 24, 2265-2269.

19. Wen, H., T. Aji, Y. M. Shao. Diagnosis_and management against the complications of human cystic echinococcosis.- Front. Med. China, 4, 2010, No 4, 394-398.

20. Yalcin, E., N. Kiper, C. Tan, U. Ozcelik, D. Dogru, N. Cobanoglu, et al. The role of human leucocyte antigens in children with hydatid disease: their association with clinical condition and prognosis.Parasitol. Res., 106, 2010, No 4, 795-800. 